\title{
Neurosurgery in Treatment of Prolactin-Secreting Pituitary Adenomas
}

\author{
Oleksandr Voznyak ${ }^{1}$ \\ ${ }^{1}$ Centre of Neurosurgery, Clinical Hospital “Feofaniya," Kyiv, Ukraine
}

Indian J Neurosurg 2021;10:91-91.

Prolactin-secreting pituitary adenomas compromise more than $50 \%$ of all hypophyseal adenomas. The typical clinical manifestations in women are amenorrhea with lactorrhea. Men suffer most often from decreased libido, gynecomastia, and obesity. The treatment is still challenging due to the need of reproductive function return in addition to tumor growth control.

It has been more than a century since prolactin-secreting pituitary adenomas are treated surgically. Overall, surgery was the only effective method of treatment during this period of time. Radiotherapy did not show enough efficacy as the main method of treatment and was abandoned consequently.

The introduction of dopamine agonists was revolutionary, and the era of conservative treatment of prolactinsecreting adenomas (PSA) started in the 1970s. The thoughts about exclusively conservative treatment began to spread. However, the analysis of clinical data did not meet those expectations, and even cabergoline showed efficacy rate up to $70 \%{ }^{1}$ In addition, approximately $15 \%$ of patients experienced dopamine agonists' intolerance, making its application not universal. The next issue is the recurrence following dopamine agonists' withdrawal. ${ }^{2}$ This creates the tendency for lifelong drug taking. Hyperprolactinemia restoration is reported in 55\% of cases after pharmacy abolishment. It is worth mentioning the side effects that are well seen during the follow-up period and even better described in "internet forums" created by patients themselves.

Also, the misdiagnosis of truly secreting prolactinomas and adenomas, which create secondary hyperprolactinemia cause obstacles for their effective treatment: last mentioned are not sensitive for conservative treatment.

In recent decades, a technique of transsphenoidal microsurgical as well as endoscopic removal of pituitary adenomas has developed rapidly. The level of surgical complications decreased to $0.1 \%$. In relation to noninvasive forms of tumors,
Address for correspondence Oleksandr Voznyak, MD, PhD, Centre of Neurosurgery, Clinical Hospital "Feofaniya," Kyiv, Ukraine (e-mail:drvoznyak@gmail.com).

the efficacy exceeded the conservative method, and the result is reached almost immediately after surgery. ${ }^{3}$

From the financial point of view, expenses for time-consuming cabergoline are higher than surgical treatment.

According to recent data, less than $10 \%$ of prolactinomas are treated surgically. These are patients who are intolerant to cabergoline, did not gain significant effect by conservative treatment, or choose surgery by themselves. We claim that endocrinological remission could be reached in $50 \%$ of all patients and in more than $70 \%$ of noninvasive purely endosellar cases. A marked tendency for worse outcome of pituitary adenomas' excision is seen in patients who were previously treated with dopamine agonists. ${ }^{4}$

According to gained clinical data and notable controversies, treatment algorithm should be reviewed, and surgical indications should be extended. Atleast patients, must be better informed about all treatment options for prolactinoma and their related efficiency potential.

\section{Conflict of Interest}

None declared.

\section{References}

1 Sala E, Bellaviti Buttoni P, Malchiodi E, et al. Recurrence of hyperprolactinemia following dopamine agonist withdrawal and possible predictive factors of recurrence in prolactinomas. J Endocrinol Invest 2016;39(12):1377-1382

2 Dekkers OM, Lagro J, Burman P, Jørgensen JO, Romijn JA, Pereira AM. Recurrence of hyperprolactinemia after withdrawal of dopamine agonists: systematic review and meta-analysis. J Clin Endocrinol Metab 2010;95(1):43-51

3 Vilar L, Abucham J, Albuquerque JL, et al. Controversial issues in the management of hyperprolactinemia and prolactinomas - An overview by the Neuroendocrinology Department of the Brazilian Society of Endocrinology and Metabolism. Arch Endocrinol Metab 2018;62(2):236-263

4 Donegan D, Atkinson JL, Jentoft M, et al. Surgical outcomes of prolactinomas in recent era: results of a heterogenous group. Endocr Pract 2017;23(1):37-45
DOI https://doi.org/ $10.1055 / \mathrm{s}-0041-1732801$ ISSN 2277-954X
(C) 2021. Neurological Surgeons' Society of India.

This is an open access article published by Thieme under the terms of the Creative Commons Attribution-NonDerivative-NonCommercial-License, permitting copying and reproduction so long as the original work is given appropriate credit. Contents may not be used for commercial purposes, or adapted, remixed, transformed or built upon. (https://creativecommons.org/licenses/by-nc-nd/4.0/).

Thieme Medical and Scientific Publishers Pvt. Ltd. A-12, 2nd Floor, Sector 2, Noida-201301 UP, India 